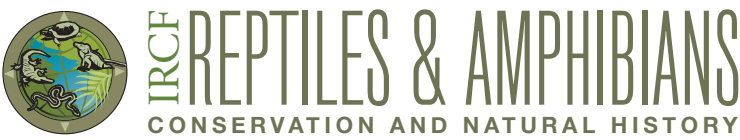

\section{Predation of a Utila Spiny-tailed Iguana, Ctenosaura bakeri (Iguanidae), by a Central American Boa, Boa imperator (Boidae), on Utila, Isla de la Bahia, Honduras}

\author{
Daisy Maryon ${ }^{1,2}$, Tom W. Brown ${ }^{2}$, and David C. Lee ${ }^{1}$ \\ ${ }^{1}$ University of South Wales, Pontypridd, UK (dfmaryon@gmail.com) \\ ${ }^{2}$ Kanahau Utila Research and Conservation Facility, Isla de Utila, Honduras
}

$\mathrm{T}$ The Utila Spiny-tailed Iguana (Ctenosaura bakeri) is a critically endangered species endemic to the island of Utila in the Bay Islands Archipelago off the northern coast of Honduras (Maryon et al. 2018). Despite being the focus of a long-term conservation program, in-situ interactions of C. bakeri with natural predators are rarely observed or documented. Only Gutsche (2005) documented predation events involving a bird (Great-tailed Grackle, Quiscalus mexicanus) and the Central American Boa (Boa imperator). During fieldwork from 2012 to 2019, we recorded evidence of C. bakeri as prey of at least two snake species, expanding on current understanding of predation of this species. Primarily, expand- ing on the report of Gutsche (2005), we herein document two further instances of boas preying on C. bakeri.

The first observation in April 2016 took place in coastal beachfront vegetation on the northern side of the island at a known nesting beach for $C$. bakeri. An adult B. imperator (approx. $1.2 \mathrm{~m}$ total length) was observed constricting an adult female $C$. bakeri (Fig. 1). The lack of an ongoing struggle between predator and prey suggested that the iguana had already died through constriction. The iguana was a known female that had been captured and marked in the course of our long-term radio-telemetry project. Using data collected two days prior, we were able to confirm that the female was

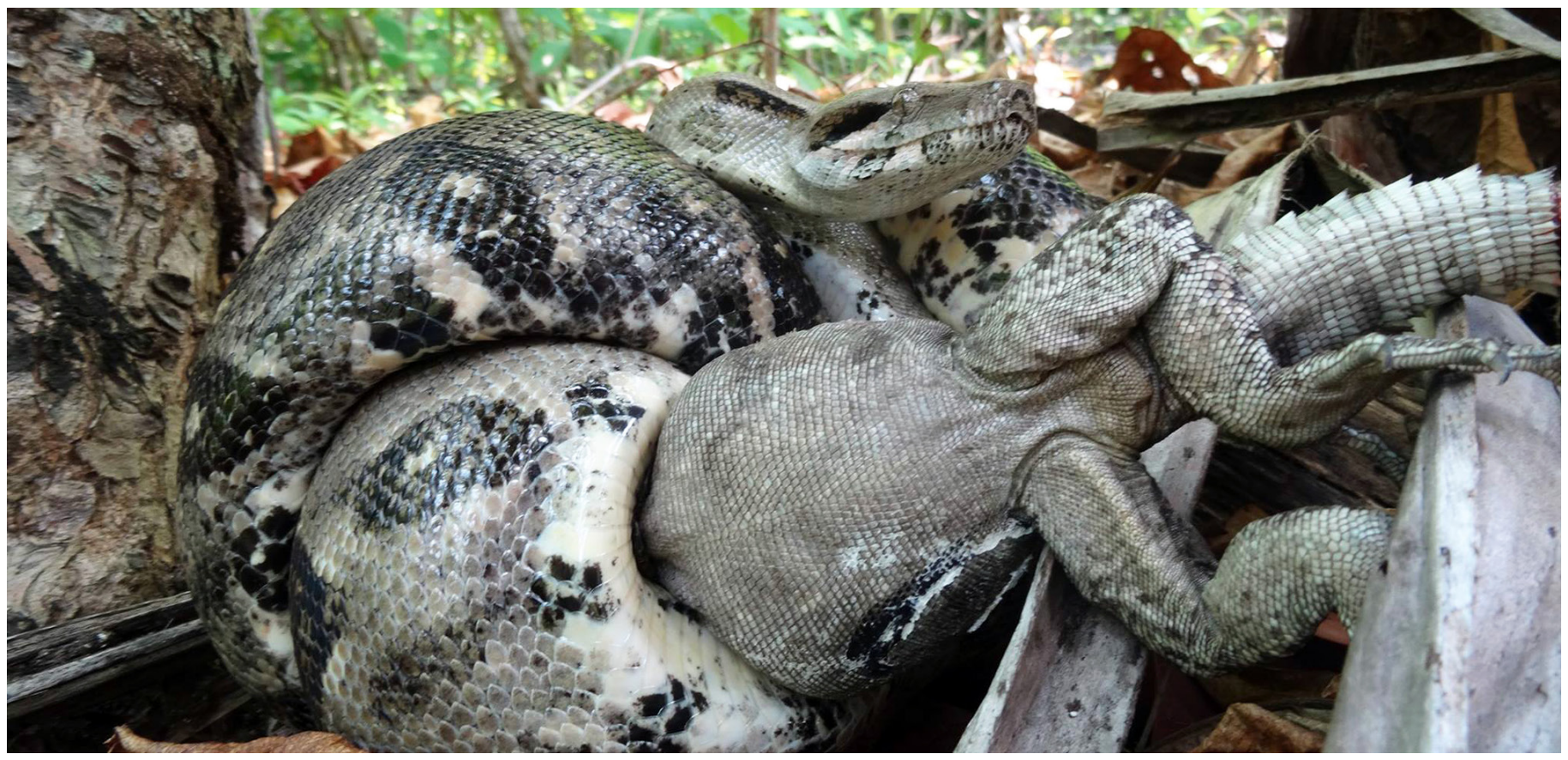

Fig. 1. A Central American Boa (Boa imperator) constricting a female Utila Spiny-tailed Iguana (Ctenosaura bakeri) in beachfront vegetation on Utila. Photograph by Tom Brown. 
gravid and had a snout-vent length (SVL) of $192 \mathrm{~mm}$, a tail length of $276 \mathrm{~mm}$, and body mass of $282 \mathrm{~g}$. As the observation occurred on the vegetated outskirts of a beach during the nesting season for $C$. bakeri, we assume that the female was searching for a suitable nesting site. Although we did not witness the initial capture, the snake was constricting the iguana on the ground, and no suitable perches for either animal were in the immediate vicinity. These conditions suggest that the boa opportunistically preyed on the iguana from its diurnal retreat alongside a large piece of driftwood beneath the shade of beachfront palm and almond trees. To minimize further disturbance to the snake, we did not stay to observe the process of complete ingestion.

A second observation of $B$. imperator preying on $C$. bakeri occurred around 1000 h on 15 February 2017. While surveying Red Mangrove (Rhizophora mangle) habitat on the western side of Utila, we observed a large adult boa (ca. 2 $\mathrm{m}$ in length) constricting a large adult male $C$. bakeri (total length approx. $55 \mathrm{~cm}$ ) about $11 \mathrm{~m}$ high in the canopy of a Red Mangrove. We did not witness capture and, at the time of our observation, the boa was maneuvering its prey prior to ingestion and the weight of the iguana caused it to swing from a branch during the process. We observed and photographed the event for about $15 \mathrm{~min}$ before continuing surveys.

These observations indicate that predation of $C$. bakeri by $B$. imperator can occur on the ground or in the canopy and within both primary mangrove and coastal habitats. Boa imperator has a wide and generalist diet (Greene 1983; Bakkegard and Timm 2001) and is capable of ingesting most prey items that it overpowers (Brown 2018). It is a common species throughout its range and is well-adapted to a range of habitats (Greene 1983; Köhler 2003). Since island forms of $B$. imperator tend to be more arboreal (Reed et al. 2007), treedwelling iguanas such as $C$. bakeri may be an important and regular food source. On Utila, B. imperator is well known as a predator of iguanas, and some island residents reinforce this with vivid descriptions of >24-hour battles between large adult iguanas and boas. Similar predator-prey interactions involving B. imperator and Black-chested Spiny-tailed Iguanas ( $C$. melanosterna) on the Cayos Cochinos off the northern coast of Honduras were reported by Montgomery et al. (2012).

In addition to $B$. imperator, we briefly note the likelihood of predation by other snakes on Utila. On one occasion in August 2013, a Brown Vine Snake (Oxybelis aeneus) was observed preying on a hatchling $C$. bakeri along a beachfront (A. Martinez, pers. comm.). Its larger congener, the Green
Vine Snake (O. fulgidus) also will prey on juvenile or hatchling iguanas (e.g., C. similis; Brown et al. 2019). We frequently found Mexican Parrot Snakes (Leptophis mexicanus) and Salmon-bellied Racers (Mastigodryas melanonotus) active near hatchlings that were basking in mangrove and coastal vegetation. Since the diets of all of these snakes includes small lizards (Köhler 2003), we infer that all of these species contribute to natural predation pressure on juvenile C. bakeri.

\section{Acknowledgments}

We thank Kanahau Research and Conservation Facility for the resources to conduct population monitoring of Ctenosaura populations on Utila. A special thanks to Stesha Pasachnik and Thijs van Den Burg for their assistance during fieldwork, to the International Iguana Foundation and Mohammed bin Zayed Species Conservation Fund for funding our research, and to all volunteers who participated in field surveys. Herpetological observations and data collection were performed under valid permits Resolution-De-MP-016-2016 and Resolution-De-MP-54-2017 issued by Instituto Nacional de Conservación y Desarrollo Forestal, Áreas Protegidas y Vida Silvestre (ICF), Tegucicalpa, Honduras.

\section{Literature Cited}

Bakkegard, K.A. and R.M. Tim 2001. Boa constrictor (Boa Constrictor). Diet. Herpetological Review 32: 261-262.

Brown, T.W. 2019. Fowl play: A failed predation attempt of an adult turkey Meleagris gallopavo (Linneaus, 1758) (Chordata; Phasianidae) by Boa imperator (Daudin, 1803) (Squamata; Boidae) in Cayo District, Belize. Captive and Field Herpetology 3: 55-59.

Brown, T.W., A.C. Algar, and N. Molina. 2019. Predation of the lizards Ctenosaura similis (Iguanidae) and Hemidactylus frenatus (Gekkonidae), by the Green Vine Snake Oxybelis fulgidus (Colubridae) on Utila Island, Honduras. Sauria 41(1): 55-62.

Greene, H.W. 1983. Boa constrictor (boa, bequer, boa constrictor), pp. 380-382. In: D.H. Janzen (ed.), Costa Rican Natural History. The University of Chicago Press, Chicago, Illinois.

Gutsche, A. 2005. Ctenosaura bakeri (Utila Spiny-tailed Iguana). Predation. Herpetological Review 36: 317.

Köhler, G. 2003. The Reptiles of Central America. Herpeton, Verlag Elke Köhler, Offenbach, Germany.

Maryon, D., D. Ardon, A. Martinez, S. Clayson, and S.A. Pasachnik. 2018. Ctenosaura bakeri. The IUCN Red List of Threatened Species 2018: e.T44181A125203850.

Montgomery, C.E., S.A. Pasachnik, L.E. Ruyle, J.A. Frazier, and S.E.W. Green. 2014. Natural history of the Black-chested Spiny-tailed Iguanas, Ctenosaura melanosterna (Iguanaidae), on Cayo Cochino Menor, Honduras. The Southwestern Naturalist 59: 280-85.

Reed, R.N., S.M. Boback, C.E. Montgomery, S. Green, Z. Stevens, and D. Watson. 2007. Ecology and conservation of an exploited insular population of Boa constrictor (Squamata: Boidae) in the Cayos Cochinos, Honduras, pp. 389-403. In: R.W. Henderson and R. Powell (eds.), Biology of the Boas and Pythons. Eagle Mountain Publishing, Eagle Mountain, Utah. 